Western University

Scholarship@Western

6-18-2018

\title{
GSA members' experiences with a structured program to promote well-being
}

Alicia A. Lapointe

Western University, alapoint@uwo.ca

Claire Crooks

Western University, ccrooks@uwo.ca

Follow this and additional works at: https://ir.lib.uwo.ca/csmh-articles

Part of the Gender and Sexuality Commons, and the Mental and Social Health Commons

\section{Citation of this paper:}

Lapointe, Alicia A. and Crooks, Claire, "GSA members' experiences with a structured program to promote well-being" (2018). Journal Articles. 8.

https://ir.lib.uwo.ca/csmh-articles/8 


\section{GSA members' experiences with a structured program to promote well-being}

\section{Alicia Lapointe \& Claire Crooks}

To cite this article: Alicia Lapointe \& Claire Crooks (2018): GSA members' experiences with a structured program to promote well-being, Journal of LGBT Youth, DOI:

10.1080/19361653.2018.1479672

To link to this article: https://doi.org/10.1080/19361653.2018.1479672

曲 Published online: 18 Jun 2018.

Submit your article to this journal

Q View related articles ¿

View Crossmark data $₫$ 


\title{
GSA members' experiences with a structured program to promote well-being
}

\author{
Alicia Lapointe (D) and Claire Crooks \\ Faculty of Education, Western University, London, Ontario, Canada
}

\begin{abstract}
LGBT2Q+ youth experience significant oppression in schools and there are few evidence-informed programs to promote well-being. This study describes the experiences of youth who participated in a 17-session structured mental health promotion program through their GSAs. Focus groups were conducted with 15 youth. Results indicated that the program helped youth validate and affirm their identities and expressions. The program also afforded youth structured opportunities to identify and process minority stressors, and develop essential coping strategies to bolster their well-being and manage their toxic relationships.
\end{abstract}

\section{ARTICLE HISTORY}

Received 13 November 2017

Revised 17 March 2018

Accepted 18 May 2018

\section{KEYWORDS}

Coping strategies; GSA; healthy relationships; LGBT2Q youth; mental health; program

\section{Introduction}

The Canadian education system is an oppressive place for LGBT2Q+ youth (Taylor et al., 2011). There is a call for evidence-informed programs to affirm and celebrate LGBT2Q+ students' identities/ways of being and expressions, and assist these youth cope with minority stress (Austin \& Craig, 2015a, b; Craig, 2013; Craig, Ashley, \& McInroy, 2013; Heck, 2015). Schools are logical settings to deliver programs designed for promote wellness among LGBT2Q+ youth because they have historically been hard to reach through traditional community services (Craig, 2013). Heck (2015) argues that school programming has " ... the potential to address the unique stressors that place LGBT2Q youth at risk within the same ecological system where these stressors are frequently encountered" (p. 2). Gender and Sexuality Alliances $(G S A)^{1}$ are relevant venues to reach LGBT2Q+ students and deliver healthy relationships and mental health promotion programming at school (Heck, 2015; Lapointe, Dunlop, \& Crooks, accepted) and research is needed to examine the extent to which club members benefit from such programing because "... the influence of GSAs on psychological wellbeing may be related less to generic participation and more to the quality and

CONTACT Dr. Alicia Lapointe $\otimes$ alapoint@uwo.ca; Claire Crooks $\otimes$ ccrooks@uwo.ca 0 Centre for School Mental Health, 1137 Western Road, Room 1154, London, Ontario, Canada, N6G 1 G7. 
amount spent in GSA activities" (Ioverno, Belser, Baiocco, Grossman, \& Russell, 2016, p. 11-12). This paper explores how a structured healthy relationships and mental health promotion program, the Healthy Relationships Program (HRP) for Lesbian, Gay, Bisexual, Trans, Two-Spirit and Queer/Questioning, (LGBT2Q+) Youth, delivered in Gender and Sexuality Alliances (GSA), ${ }^{1}$ was perceived and experienced by club members.

Although these student-driven clubs, spaces where LGBT2Q+ youth may find safety and support (Griffin et al., 2004), are open to straight and cisgender allies (i.e., those who support LGBT2Q+ people and work to end oppression), the founding purposes of these groups are to assist marginalized youth and to build interpersonal connections and collaborative collations among their members (Miceli, 2005). Similar to regular GSA meetings, The Healthy Relationships Program for LGBT2Q+ Youth may benefit straight and cisgender students insomuch that they, like LGBT2Q+ youth, can learn about healthy relationships and develop or enhance inter/a/personal skills by participating in structured queer and transinfused programming.

\section{Supporting LGBT2Q+ youth's well-being through GSA presence and participation}

Toomey, Ryan, Diaz, and Russell's (2017) research on sexual minority-related coping emphasizes the importance of having access to and belonging to queer community (e.g., a GSA) to promote positive well-being. GSAs are school-based groups that provide safer spaces for LGBT2Q+ youth and their allies to meet, find support, socialize, develop relationships, learn about sexuality and gender-related topics, and lobby for social change (Kosciw, Greytak, Giga, Villenas, \& Danischewski, 2016; Griffin et al., 2004; Grace \& Wells, 2015; Mayberry, Chenneville, \& Currie, 2011; Mayo, 2013, 2015; Miceli, 2005; St. John et al., 2014; Taylor et al., 2011). Although GSAs and youth members' experiences in them are not monolithic (Poteat, Scheer, Marx, Calzo, \& Yoshikawa, 2015; Poteat, Yoshikawa, Calzo, Russell, \& Horn, 2017), research has found that club participation positively influences youth's comfort with their sexuality (Lee, 2002) and gender expression (Walls, Wisneski, \& Kane, 2013), promotes positive connections among friends and family (Lee, 2002), and helps students end unhealthy relationships (McCormick, Schmidt, \& Clifton, 2015). Youth who attend schools with a GSA are "...much more likely to be open with some or all of their peers about their sexual orientation and/or gender identity..." (Taylor et al., 2011, p. 19). Similarly, clubspecific involvement has assisted some youth develop the confidence and courage to come out to their families (McCormick et al., 2015). Overall, GSA participation is a "... specific coping strateg[y] that [is] particularly meaningful for LGB adolescents" (Toomey et al., 2017, p. 12), especially since group settings can provide opportunities for LGBT2Q+ youth to increase their connectedness with others who experience similar minority stress (Craig, 2013). 
Large-scale American and Canadian school climate surveys have found that GSAs help foster more positive learning environments for LGBT2Q+ students (Kosciw et al., 2016; Taylor et al., 2011) and smaller-scale studies have found that sexual minorities who attend schools with GSAs report a greater sense of belonging in their school community (Lee, 2002; Toomey \& Russell, 2013). In particular, Morrison (2012) found that, for rural youth, club participation fostered muchneeded relationship development among LGBT2Q+ students and helped validate sexual diversity. On the whole, students with access to GSAs report less peer-based victimization (Kosciw et al., 2016; Marx \& Kettrey, 2016; Taylor et al., 2011), which is a significant finding because a reduction in discrimination related to gender identity and expression is likely to have a positive impact on youth's mental health (Burford, Lucassen, \& Hamilton, 2017).

Although Toomey, Ryan, Diaz, and Russell (2011) retrospective study with 245 LGBT young adults found that the presence of GSAs and participation in these clubs was positively associated with well-being (e.g., less depression and more positive self-esteem), Ioverno et al. (2016) did not find “... associations between GSA presence and participation and psychological well-being" (p. 11), which calls for research to explore the extent to which GSA-specific programming positively impacts students (Ioverno et al., 2016). Similarly, Poteat et al. (2017)) call for GSAs to offer structured programming, such as guided questions, to encourage youth to cope with LGBT2Q-based victimization in healthy ways. They suggest that the potential positive impacts of GSA participation may be strengthened with the delivery of evidence-informed mental health promotion programs.

\section{GSAs as optimal venues to deliver structured LGBT2Q-focused programming}

Although the field of GSA-specific program delivery is relatively new, Heck's (2015) small-scale, mixed methods study provides some insight into how structured GSA programming may benefit LGBT2Q+ youth. Heck (2015) explored the feasibility and acceptability of a GSA-based mental health promotion program for LGBT2Q+ youth. The four-session program addressed sexual and gender minority stress (Meyer, 2003; see also Austin \& Craig, 2015a; Rood, Reisner, Surace, Puckett Maroney, \& Pantalone, 2016) and promoted positive coping skills among LGBT2Q+ youth by helping them identify stressors, develop healthy coping skills, utilize cognitive skills, and discuss the merits of coming out. Brief surveys were completed by the 10 GSA members who participated in the program. Findings revealed that youth enjoyed the sessions, believed the content was relevant, and gained new knowledge from participating in the program, but students desired more youth-directed discussions and games/activities. Based on these findings, Heck suggested that it was feasible to integrate a structured program in this context (see also Lapointe et al., accepted). The Healthy Relationships Program (HRP) for Lesbian, Gay, Bisexual, Trans, Two-Spirit and Queer/Questioning, (LGBT2Q+) Youth, shares some of the strengths of the program piloted by Heck, but also builds 
on it in the following way: consistent with GSA member's requests for more participant-directed discussion (Heck, 2015), our program was designed to encourage student-driven conversation and engage youth in participatory activities that promote healthy peer relationships. Such a focus is paramount because positive interpersonal connections have been found to increase program retention among youth (McGuire, Dworkin, Borden, Perkins, \& Russell, 2016).

\section{Healthy relationship program (HRP) for LGBT2Q+ youth development and overview}

The HRP for LGBT2Q+ Youth aims to bolster positive mental wellness and relational skill development among sexual (e.g., pansexual, lesbian, gay, bisexual, asexual, etc.), gender (e.g., Two-Spirit, gender non-conforming, trans, genderqueer, non-binary, bigender, etc.), and romantic (e.g., aromatic, demiromantic, polyamorous) minorities. It was adapted from the Healthy Relationships Plus Program

\begin{tabular}{|c|c|}
\hline Session Number & Session Topic \\
\hline Session 1 & I Have a Voice: Introduction to the Program \\
\hline Session 2 & Mine to Name: Identities/Ways of Being \\
\hline Session 2 & Recognize and Respect: Values and Boundaries \\
\hline Session 4 & My Journey: Coming Out \\
\hline Session 5 & My Mind Matters: Mental Health and Well-Being \\
\hline Session 6 & In the Know: Impacts of Substance Use and Abuse \\
\hline Session 7 & I Belong: Communities and Connections \\
\hline Session 8 & My Super-Power: Coping with Challenges \\
\hline Session 9 & We All Have a Say: Rights / Responsibilities / Consent \\
\hline Session 10 & My Voice, Your Voice: Active Listening and Communication \\
\hline Session 11 & Right and True: Communication Styles \\
\hline Session 12 & Words and Actions: Communicating Through Conflict \\
\hline Session 13 & Ships: Healthy and Unhealthy Relationships \\
\hline Session 14 & (Re)Building Ties: Addressing Relationship Violence \\
\hline Session 15 & My Safety: Exits and Safety Plans \\
\hline Session 16 & Allies: Being There for Others \\
\hline Session 17 & The Concluding Circle: Share and Celebrate \\
\hline
\end{tabular}

Figure 1. HRP for $L G B T 2 Q+$ Youth Sessions. 
(HRPP) - an evidence-informed, small groups universal prevention program for adolescents that promotes positive mental health and well-being, and prevents risky behaviours (The Fourth R, 2018). The program manual and associated workbook were developed in an iterative process with academics, educators, and youth (see Lapointe, 2017; Lapointe et al., accepted) and consists of 17, 45-minute sessions that are designed to validate and affirm sexual, gender, and romantic diversity, and to help LGBT2Q+ youth cope with oppression (e.g., heteronormativity, interlocking oppressions) (Meyer, 2003). Session topics are listed in Figure 1.

The HRP for LGBT2Q+ Youth legitimizes and emphasizes queer understandings of sexuality (i.e., non-binary, fluid, historically-contingent) (Sedgwick, 1990/ 2008) and trans-formed perspectives on sex (i.e., non-dichotomous; subconscious sex, sexed embodiment) (Serano, 2007/2016; Stryker, 2006) and gender (i.e., not “... simple or natural 'givens"' (Elliot \& Roen, 1998, p. 237). This stance is critical because sexual and gender minority identities/ways of being and expressions are routinely 'Othered' (i.e., positioned as abnormal, unnatural, immoral, undesirable, etc.) in the education system (Kumashiro, 2002). Programmatic sessions engage youth in a variety of topics (e.g., microaggressions, substance mis/ab/use, healthy relationships, communication skills, etc.), all of which are grounded in queer and trans-informed understandings of sex, sexuality, and gender.

Below, we briefly describe two program sessions to help contextualize the study findings. Session two in the program, Mine to Name: Identities/Ways of Being, begins with an opening circle where youth are encouraged to share their names and pronouns (optional), and one word to describe how they are feeling. Building in sustained opportunities to share current pronouns, if participants wish to, helps expose cissexist assumptions (McGlashan \& Fitzpatrick, 2018), and works to affirm shifts in subjectivities over space and time (Mayo, 2017). However, some GSA members have suggested that this practice "... reinforce[s] the dominance of cisgendered people and while it invite[s] more complex identification, without knowing the ramifications of that identification, the invitation seem [s] incomplete" (Mayo, 2017, p. 68). This session goes beyond simply naming to more deeply explore dimensions of identities. Participants are divided into smaller groups and tasked with writing or drawing words, images, and/or symbols on chart paper to express their understanding of the following six concepts: sexual orientation, romantic orientation, sex, gender identity, gender expression, and identities/ways of being. Having an explicit focus on 'identities/ways of being' is significant because, as Hulko and Hovanes (2018) contend, “... the multiplicity and interaction of identities frames [sexual and gender minority youth's] experience" (p. 446-447). Chart papers are rotated until each group has provided responses for each concept. To debrief the activity, youth discuss what they have learned. To close the session, each youth is invited, once again, to share their name and pronouns and complete the following sentence, "What I love about my identities/ways of being and expressions is... " Session four, My Journey: Coming Out, starts by asking each youth to provide a response to the following 
question, "What does coming out mean to you"? Thereafter, youth examine eight coming out infographics (see Sex Ed Plus, 2014) and identify the affirmative message embedded in each statement (e.g., coming out is more than being gay; my coming out experiences unfold each day; my safety is important when considering coming out, etc.). The session finishes with youth sharing coming out advice/ strategies.

\section{Methods}

\section{Qualitative approach}

This pilot study aimed to produce in-depth and detailed accounts (Patton, 2002) of youth's experiences with and perspectives on the HRP for LGBT2Q+Youth. By exercising a qualitative approach, we foregrounded the lived experiences and insights of LGBT2Q+ youth. By listening to and privileging GSA members' perspectives we uncovered the “... individual meaning" (Patton, 2002, p. 16) that youth associated with program participation. The following research question guided this investigation: 1) What were youth's experiences with the HRP for LGBT2Q+ Youth?

\section{Participants}

In total, approximately 65 youth from seven urban and one rural school located across two public secular secondary school districts participated in the program over the course of the 2016-2017 academic year. Based on information provided by facilitators, groups completed a variable number of HRP for LGBT2Q+ Youth sessions (mean $=11$ ). Of the 65 program participants, 15 youth from six urban schools provided feedback on the HRP for LGBT2Q+ Youth in June 2017: Jordan, Casey, and Brooks (school 1); Alex, Sidney, Berni, and Cori (school 2); Rae and Cameron (school 3); Jean ${ }^{2}$ (school 4); Cass, Harley, and Morgan (school 5); and Gates and Jesse (school 6). All participant names are pseudonyms and we use gender neutral pronouns when referring to youth because we did not inquire about their self-identification. Moreover, no demographic data was collected from youth (e.g., race, gender identity, sexual orientation, etc.), which is a limitation of this study since participant's insights cannot be not fully contextualized vis-à-vis their lived experiences. Yet, some youth voiced their subjectivities when providing answers, which helped provide a more robust picture of the meaning they associated with program participation.

\section{Procedure}

An email was sent to all GSA advisors in one large and one small publicly-funded secular school board to invite them to learn about the HRP for LGBT2Q+ Youth. After interested educators attended a full-day training session that was held in November 2016, all club advisors elected to deliver the program based on the needs 
and desires of GSA members. Towards the end of the school year, all students who participated in the program across the eight school sites were provided a Letter of Information and Consent form by their GSA advisor at one of their regular group meetings. Those who were interested in providing feedback on the program were asked to complete and return a consent form to their advisor. After all interested youth returned their consent forms, the first author arranged to meet consenting GSA members at their school to complete a focus group. All protocols received ethical approval from the institutional review board as well as the school board research office.

\section{Data collection}

To elicit feedback on the program, the first author facilitated a focus group at six of the eight school sites. Focus groups were not conducted at two schools because no youth came forward to participate at one, and a group emergency at another school derailed data collection (i.e., the group had to debrief a targeted attack on the GSA's anti-heteronormative school-wide campaign). We choose to facilitate focus groups because this data collection method produces “... high-quality data in a social context where people can consider their own views in the context of the views of others" (Patton, 2002, p. 386). Focus groups were facilitated during regularly-scheduled GSA meetings, often in a separate room from the larger group. These sessions lasted approximately 45 minutes and the number of participants in each session ranged from one to seven. Focus group questions are provided in Appendix A. Focus groups were transcribed with Trint voice-to-text software and were reviewed and revised by the first author based on the audio recordings.

\section{Data analysis}

Thematic analysis was employed to make sense of the data, which involved looking for patterns and themes across the school sites (Patton, 2002). More specifically, with this iterative process the first author became familiar with the data, inductively generated codes, and searched for, reviewed, and named themes (Braun \& Clarke, 2006). Commonalities among youth's perspectives and experiences that surfaced during focus groups were documented by scribing analytic memos after each session (Patton, 2002). By conducting all focus groups, and reviewing the totality of transcripts and scribing emerging patterns across the school sites, the first author began to loosely theme the data by deciding "... what things go together to form a pattern, what constitutes a theme, what to name it, and what meanings to extract..." (Patton, 2002, p. 442). For example, GSA members indicated that the program promoted youthled discussion (i.e., a pattern), which enabled participants to share and learn from each other (i.e., a theme). 


\section{Positionality of researchers}

The first author, a queer and gender non-conforming educator, youth group facilitator, and scholar in the field of GSAs and youth activism, along with the second author, an allied academic who develops, implements, and evaluates a variety of mental health promotion and positive relationships programs, are writers of the HRP for LGBT2Q+ Youth and thus, have an inherit interest in the program's success. The first author attempted to offset potential biases by purposefully inquiring about the program's weaknesses. From such probing, youth identified that the following sessions required further work: Session 5 - My Mind Matters: Mental Health and Well-Being, and Session 6 - In the Know: Impacts for Substance Use and Abuse. Youth suggested that we broaden the scope of these sessions and infuse principles of harm reduction. Despite our efforts to elicit negative feedback, youth's responses were overwhelmingly positive, unlike the feedback to our prior iteration of the program, which identified the need for substantial revisions (see Lapointe et al., accepted).

\section{Results}

In this section, we describe the affirming nature of the HRP for LGBT2Q+ Youth from the vantage point of GSA members, and explore how programmatic strategies prompted youth to discuss relevant topics in-depth, build supportive networks, express themselves, and develop proactive coping strategies to manage minority stress.

\section{Introducing important topics and promoting in-depth discussions}

Consistent with Ioverno et al. (2016) argument that specific GSA activities, rather than generic club participation, is likely to have a greater impact on students' wellbeing, the HRP for LGBT2Q+ Youth introduced club members to new and salient topics. It also promoted in-depth discussions about significant issues that they face (e.g., coming out). As Sidney noted:

... I feel like the program helped to prompt some topics and, like, guide some of the conversations, whereas, like, we might not have brought up the same topics... the program sort of brought up some topics we wouldn't have considered, like, by ourselves... it did a better job at, like, promoting topics and discussion than we would have by ourselves.

Harley echoed Sidney's insights when they relayed that the program emphasized topics that they may have otherwise overlooked: "I think it's a good idea to just, kind of, go over some topics that we might miss as a group." In this way, Jordan suggested that following a structured program within the GSA “... allow[ed] for learning opportunities... " When asked if the group brought up similar topics in their regular group meetings, Jesse voiced: "We might, like, brush up on them. But, I don't think it would be to, like, the same extent... "Similarly, Morgan 
communicated that some program topics may have been introduced, but certainly not in as much depth:

I feel like in a way those things would be mildly kind of brought up, like underlying. Like things like that would probably be mentioned... if somebody came to GSA and was talking about, like, their parents and how bad it is at home... Like, healthy relationships would probably get talked about there and some coping mechanisms might be brought up, but it would never be an actual full lesson I don't think.

Altogether, GSA members enjoyed the structure the program provided because it enabled them to explore new topics or examine previously-identified themes in more depth. Such findings reinforce the acceptability of implementing a structured mental health promotion program within GSA contexts (Heck, 2015).

\section{Exploring and affirming sexual and gender diversity}

Consistent with Craig et al. (2013) work, which stresses the significance of LGBT2Q+ affirmative programming, the HRP for LGBT2Q+ Youth aimed to acknowledge and celebrate the plethora of identities and expressions within LGBT2Q+ communities. Participants valued the program because it helped them figure out and affirm who they are, which is particularly significant for trans and gender diverse individuals who are often dehumanized (Serano, 2007/2016), unsupported, rejected, and ignored by society (Rood et al., 2016). In particular, Sidney discussed how having a validating venue was vital: “... I, like, crave, like, spaces to talk about LGBT issues and to talk about myself in a space where I know someone's not going to be like, 'well, that's weird."” They went on to explicitly describe how they enjoyed session two because it prompted identity exploration and authorization:

... I liked session two, the mine to name one, because I like having, like, a space where I could describe my own identity and it would be valid and people wouldn't be like, 'that's not real.' Cause, like, that happens. But, like, I felt like having that sort of space to talk about that... I liked that session a lot.

Such an affirming focus is imperative because LGBT2Q+ identities, expressions, and experiences have historically been and continue to be stigmatized and pathologized in and through institutions, such as schooling (Grace \& Wells, 2015). For Casey, the program helped "... to sort of figure out labels if you want to label yourself” and Cori described how program participation helped them discover more about themself:

I think I discovered a little more of myself. You know, I started kind of realizing, 'Hey, like, maybe there's more to gender for me personally'... kind of like figuring out who I am... because, you know, when you talk about... the spectrum and, you know, where you can fit. And, like, I was kind of imagining in my head and I was like, 'hey, this kind of makes sense'... just helping me personally with things like that. 
Both Casey and Cori's reflections demonstrate how the HRP for LGBT2Q Youth provided a crucial opportunity to discuss and validate their use of "... various labels over time and [how they] had experimented with diverse ways of expressing their identities through their young lives..." (Hulko \& Hovanes, 2018, p. 440).

Similar to Casey and Cori, Cass voiced how the program provided a muchneeded outlet to express and legitimize an “... understanding regarding [their] own gender that differs from [their] assigned and socialized gender" (Serano, 2007/2016, p. xv):

... I feel like also having these lessons kind of - I don't want to say gave us pride. No, you know what? It did. Like, it gave us, like, pride in ourselves and the ability to be confident and be, like, 'no, this is what I am. Like, it's not a phase' because I thought I was gender fluid. I thought I was just, 'ooh, I like to swing back and forth.' But it was actually - I was just trying to hold on to some of my femininity because I wanted to like give my mom the daughter she wanted. But after going to some of these lessons both last year and this year, I ended up coming out... So, I really feel like it gave me the ability to look at myself and look inside and be like, 'OK, yeah no. I'm not, I'm not female. Like, I feel like a male. Like, this is who I am. I shouldn't have to hold on to something that's killing me because my mom wants that.' And it really taught me the ability to kind of let that go and to be like, 'alright, you know, hello this is the new me.'

Here, Cass described how the program supported their felt sense of gender because it provided a venue for self-reflection, exploration, and affirmation; it enabled Cass's trans masculine identity to be viewed and treated as valid, rather than troublesome (Serano, 2007/2016). Overall, youth described how the HRP for LGBT2Q+ Youth prompted them to explore and affirm their LGBT2Q+ identities beyond that of which they generally experience through regular GSA participation.

\section{Discussing and contemplating coming out}

Consistent with Meyer's (2003) minority stress model, many participants indicated that they concealed their sexuality and/or gender identity from their families. Since many GSA members were contemplating coming out or experiencing difficulties associated with coming out at home, there is a clear need for programming to help them navigate and cope with hetero/cissexism (Austin \& Craig, 2015b; Craig, 2013), particularly for racialized youth and/or those with religious upbringings (Hulko \& Hovanes, 2018). For example, Gates declared: “... coming out; that can be very difficult for some people, especially depending on family situations and beliefs... a lot of my friends - are unsure about how to come out to their parents and their friends and stuff." For Alex, coming out as trans was particularly challenging: “... I feel like for some people coming out is a bit of, it's a bit of a difficult situation. Like, at least for mine. My situation was more just awkward and unpleasant." The HRP for LGBT2Q+ Youth aims to support youth as they navigate coming out and provide a pointed opportunity for them to share their stories. Mayo's (2017) research showcases the 
importance of having such discussions in GSAs and Craig (2013) notes, "Sharing [coming out] experiences in group can have a powerful impact on decreasing SMY's [sexual minority youths'] sense of isolation during such potentially stressful periods" (p. 374).

By participating in the program, youth's experiences with coming out were validated as an ongoing process. For example, Alex voiced that the coming out affirmations in session four reinforced their understanding of coming out as an individual decision that is impacted by a variety of factors (e.g., safety), spotlighting how "... context plays a part in the way youth choose to term their sexuality and gender identities" (Hulko \& Hovanes, 2018, p. 446):

... the coming out session, like, the 'my journey one,' is important because I feel like it's important to talk about coming out and that you don't to come out until you're ready. Like, you don't have to be forced to come out, especially for people who come to [GSA] who aren't out with their family. Like, they come for a space to talk about that.

Besides validating coming out as a process, the HRP for LGBT2Q+ Youth encouraged GSA members to listen to and learn from each other, which helped youth build supportive networks, as Harley expressed: “... the coming out lesson got us all talking and maybe learning more about each other and are situations at home, which led to better support systems." Such a focus helped youth recognize that "... they could rely on the support and affirmation of their GSA peers if their coming out experience[s] [were] negative" (McCormick et al., 2015, p. 76). Bernie echoed Alex and Harley's insights in that the program helped broaden their understanding of coming out and reassure them because their group members could understand and relate to their experiences:

One of my favorite sessions were the, umm, identities/ ways of being - session two - and also coming out session, four, because I thought it was important to kind of, like, broaden our views of, like, what coming out is. 'Cause a lot of people have a very narrow view of what it is but, it's a very different experience for different people. And it was reassuring to hear about other people's experiences and also things that you can do to make it better for yourself, which I thought was really important... it was just really reassuring to be able to talk about it with people who, like, understand what you're talking about - that's really nice.

Sharing and learning about others' experiences was especially important for Jean who was strategizing how to come out to their parents. Hearing other students' stories and learning about the positive and negative aspects of coming out helped them decide how they might go about coming out to their family:

... I liked the coming out, like session four. It was kind of like just everyone kind of shared some of stories or are their plans for coming out... Because, like, I haven't officially, like, kind of, to like friend groups, but not really to parents. And I was kind of listening to stories saying, 'oh this is something I could do, or I could wait.' Like, kind of getting ideas for that... And I really liked that... everyone just kind of talked like, a plan, yeah, plans or stories things like that and kind of just experience both negative and 
positive. And then I was kind of like, 'oh, I understand that. I get that or, like, that's a good thing to know... I liked hearing... everyone else's experiences and I'm like, 'I might use that.'

Jean's commentary reflects Heck's (2015) assertion that “... youth who are not 'out' to their parents many find school-based programming appealing because it could mitigate risks associated with adverse parental reactions. Such programming could also help adolescents improve their ability to assess how individuals may respond to their LGBTQ2 status and cope with negative responses when they are encountered" (p. 2).

\section{Sharing with and learning from peers}

Consistent with Heck's (2015) programmatic recommendations, the HRP for LGBT2Q+ Youth promoted youth-led discussion, which enabled participants to share and learn from each other, as Jean voiced: “... this kind of gives us a way to talk to each other and share opinions and all that." Jean elaborated further by stating:

You learned a lot about other people's experiences and all that. Because it's all us talking about that and it's kind of like, 'oh, everyone kind of goes through it slightly differently' and it was kind of getting other people's views and all that.

Like Jean, Sidney appreciated that the program emphasized youth-directed conversations:

... I feel like I did, like, learn about other people's experiences and I, like, learned stuff about myself from that and it, sort, of broadened my understanding... I liked being able to talk about my own experiences and maybe helping other people broadening their understanding or like educate some people about things they might not know about. Umm, and I thought that that was, like, a really important part of the session. I really liked that that came about through the session.

Jesse believed that such student-led discussions were foundational to developing a supportive network and making friends with fellow GSA members:

It was just nice to talk to, like, your peers 'cause they're going through, like, kind of the same thing... and just talking about, like, all these things with them, kind of like can comfort you and you can, like, make more friends and stuff 'cause you have, like, more people to talk to...

Although GSA have been found to help youth develop rewarding relationships with their clubmates and local community members (St. John et al., 2014), participants in this study explicitly discussed how the HRP for LGBT2Q+ Youth helped build a dialogic space for disclosing experiences with minority stress and cultivate a supportive network where students could learn with and from each other, and develop significant bonds with their peers. Such a focus on positive relationship development is particularly important for sexual and ethnic minority youth to keep them invested in youth development programs (McGuire et al., 2016). 


\section{Developing coping strategies}

Unsupportive and abusive families can be a tremendous source of stress for queer (Craig, 2013; Craig et al., 2013) and trans (Rood et al., 2016) persons, but as Toomey et al. (2017)) assert, little is known about how adolescents cope with sexual minority stress. Even less is known about how GSA members discuss and address cissexism, cisnormativity, and transphobia at school (Poteat et al., 2018). Unfortunately, some participants in this study had to navigate homophobic and transphobic home and school lives. Rae, for example, described their heterosexist family context:

... I've been called a faggot and told to go kill myself more by my actual brother than by my peers, which great... he's also really influenced with the fact my dad, I don't see him. Let's face it, nope. My brother still goes and sees him and eventually at one point I had to go see him and like, a lot of this language he's picking up and terminology he's improperly using and stuff like that he's learning from him. I have no influence on that, even when I went there the times he used the word Fag loosely...

Rae expressed their experiences with abusive family members, and by doing so emphasized a need to develop strategies for managing queer-specific minority stress. As Toomey et al. (2017)) reminds us, "Adolescents who navigate LGB minority stress may need to seek support that is specific to LGB issues" (p. 12); such supports can be found through GSAs, but the HRP for LGBT2Q+ Youth intentionally offers students structured support in the form of relationship development, experience-sharing, and specific coping strategies. "Helping [sexual and gender minority youth] improve their use of proactive coping is critical to youth well-being..." (Craig et al., 2013) p. 89). This necessity was emphasized by Harley, who explained: “... we're all fairly young; we're all just figuring things out for ourselves, so we don't necessarily know good ways to communicate and cope with situations yet." For many participants, such as Morgan, the HRP for LGBT2Q+ Youth provided a venue to both vent and cope with LGBT2Q+ oppression:

... these lessons was it was a safe place to have an outlet to, like, put out your anger, right?... it was a safe place where we could calmly rage at... So having these lessons a lot of times allowed kids to let all, everything that was going on inside their head out for once instead of bottling it in...

Beyond simply venting, Cass contended that GSA members shared insights on how to cope with minority stress vis-à-vis family, peer, and partner relationships:

I mean some of them got heated cause we'd get talking about our family and then the rage would appear... But, we did... get to talk about, like, 'oh, how should I handle my peers doing this? How should I handle my family doing this? How should I handle my partner doing this?'

Cass went on to explain that the program prompted discussions that helped them cope with their transphobic home life, illuminating the program's potential to promote resiliency by encouraging youth to “... use positive coping strategies that 
increase support, promote wellbeing, and focus on skills and abilities that further life-course development" (Toomey et al., 2017, p. 14):

\begin{abstract}
I feel like these lessons don't only teach us more about the community. They also see just how to cope with what could be going on at home. Because at home, like, it is just like a hellhole every time I go home. And so it's taught me how to cope with going home; it's taught me how to cope with my parents at home and I feel like it's done that for a lot of our other kids because a lot of our kids are in the same boat I am. They're either out and facing hell. They're out and they're facing some type of neglect, whether they're being blatantly ignored or they're not out and they're terrified to come out. So... it really set up coping mechanisms for a lot of our kids... it opened up our club and let other kids know that, 'hey, you're not the only one going through this. There's somebody else out there who understands. If you need to talk to anybody we're all here and we'll listen to you and we'll support you.' And some of us even have a support system that, if it gets really bad at home, 'call me and I will set up a bed for you somewhere. I don't know, but you can come and bunk at my house if it gets really bad.'
\end{abstract}

Cass's commentary demonstrates the importance of group-level coping because “... when group-level resources are absent, even otherwise-resourceful individuals have deficient coping. Group-level resources may therefore define the boundaries of individual coping efforts" (Meyer, 2003, p. 680). Jesse echoed Cass' sentiments by stating that the program was: "... all stuff to help you in life... it's to help you be... a stronger person... it was all, like, really good to see, like different ways of coping and dealing with stuff."

\title{
Discussion
}

This study utilized focus groups to explore youth participants' experiences with a structured well-being program for LGBT2Q+ youth. Study results reveal that the $H R P$ for LGBT2Q+ Youth was well-received by participants, further substantiating the acceptability of delivering mental health promotion programs in GSAs (Heck, 2015; Lapointe et al., accepted). Many students voiced that the program provided a vital outlet to explore and validate sexual and gender diversity, and it enabled them to reflect on, enhance their understanding of, and take pride in their subjectivities. Such a focus is essential because large-scale American and Canadian climate surveys have found that schools are largely inhospitable for LGBT2Q+ youth (Kosciw et al., 2016; Taylor et al., 2011; Taylor et al., 2016). Considering that $90 \%$ of trans students hear cissexist comments daily or weekly from students and $23 \%$ hear such comments from teachers (Taylor et al., 2011), the program's genderaffirming foundation is an important avenue for bolstering well-being among trans and gender diverse youth, as gender minority participants expressed in this study.

Another strength of the HRP for LGBT2Q+ Youth is that it is facilitated by caring educators, GSA advisors, who support and advocate for LGBT2Q+ youth at school. Although "GSA advisors may be one of few affirming adults accessible to LGBT youth" (Poteat \& Scheer, 2016, p. 312), research indicates that educators rarely, if ever, receive formal training for their vital position in schools (Valenti \& 
Campbell, 2009) - especially with respect to supporting LGBT youth of colour and trans youth (Poteat \& Scheer, 2016). Yet, they are tasked with promoting positive well-being and relationship development among LGBT2Q+ and allied GSA members. Since there is a lack of preservice training and Professional Development (PD) that acknowledges and validates gender diversity (Graybill et al., 2015; Taylor et al., 2016), administering anti-cisnormative training with GSA advisors - as was done in preparation for the HRP for LGBT2Q+ Youth delivery, and providing them with an evidence-informed program may enhance their capacity to support trans and gender diverse youth and promote positive well-being among all group members. As Poteat and Scheer (2016) contend, providing GSA advisors with such training and resources is essential for increasing the effectiveness with which these groups support their youth members.

Beyond legitimizing sexual and gender diversity, the HRP for LGBT2Q+Youth promoted structured opportunities to contemplate and discuss the topic of coming out. Many participants disclosed personal struggles with coming out - particularly at home, which suggests a need for GSA members to share their unique stressors with fellow group members (Mayo, 2017), build supportive networks (Craig, 2013), and gain the confidence necessary to challenge hetero/cisnormative familial assumptions (McCormick et al., 2015). According to participants, the HRP for LGBT2Q+ Youth enhanced their understanding of coming out and it offered them a pointed opportunity to reflect on and adopt specific strategies for disclosure. GSA members also described how program sessions prompted them to not only vent, but develop essential coping strategies that could apply in a variety of family, peer, and/or intimate relationships. Overall, data suggests that program-specific participation, beyond that of regular club membership, helped bolster GSA members' well-being.

\section{Limitations and future research}

Since guardian consent was required for youth under the age of 18, many GSA members were not in a position to obtain consent (e.g., not 'out' to parent(s)/ guardian(s)). This barrier demonstrated how such research requirements keep LGBT2Q+ youth from participating in projects which are intended to improve schools (Mayo, 2017). Such a requirement limited the ability of the most vulnerable youth to participate in the research; thus, findings may reflect more broadly youth with more supportive home settings or those who operate under the guise of 'allies' at home, which offers some protection from being perceived as queer or trans (Mayo, 2017). A second limitation was that groups did not have the opportunity to complete all sessions, in part because of a later than anticipated start. Thus, it is not known whether other later sessions might also have produced additional benefits. Lastly, while this study captures the experiences of youth, an important next step in developing evidence-informed mental health promotion programs would include a quasi-experimental design. 


\section{Conclusion}

This study identified significant and specific benefits of the HRP for LGBT2Q+ Youth as perceived by students. From participating in the program within their GSAs, youth reported discussing sexual and gender diversity in-depth, sharing and learning from each other, and building supportive networks with those with similar experiences. In contrast to their hetero/cisnormative schooling experiences (Kosciw et al., 2016; Taylor et al., 2011) participating in an evidenced-informed program helped GSA members validate and affirm their identities and expressions. There is evidence that the program also afforded youth structured opportunities to confront and process minority stressors, and develop essential coping strategies to bolster their well-being and manage toxic relationships.

\section{End notes}

1. Although Gay-Straight Alliance (GSA) is the brand name (Grace \& Wells, 2015), these clubs are also referred to as Gender and Sexuality Alliances (GSA), Gay-Straight-Trans Alliances (GSTA), Sexuality and Gender Alliances (SAGA), Queer-Straight Alliances (QSA) or other student-developed acronyms.

2. Jean was the sole participant at school four. As such, they partook in an individual interview, but answered the same questions that were posed during focus groups.

\section{ORCID}

Alicia Lapointe (iD http://orcid.org/0000-0002-1715-8942

Claire Crooks (D) http://orcid.org/0000-0001-8868-3181

\section{References}

Austin, A., \& Craig, S. L. (2015a). Transgender affirmative cognitive behavioral therapy; Clinical considerations and applications. Professional Psychology: Research and Practice, 46(1), 21-29.

Austin, A., \& Craig, S. L. (2015b). Empirically supported interventions for sexual and gender minority youth. Journal of Evidence-Informed Social Work, 12(6), 567-578.

Braun, V., \& Clarke, V. (2006). Using thematic analysis in psychology. Qualitative Research un Psychology, 3(2), 77-101.

Burford, J., Lucassen, M. F. G., \& Hamilton, T. (2017). Evaluating a gender diversity workshop to promote positive learning environments. Journal of LGBT Youth, 14(2), 211-227.

Craig, S. L. (2013). Affirmative Supportive Safe and Empowering Talk (ASSET): Leveraging the strengths and resiliencies of sexual minority youth in school-based groups. Journal of LGBT Issues in Counseling, 7(4), 372-386.

Craig, S. L., Ashley, A., \& McInroy, L. B. (2013). Affirmative supportive safe spaces and empowering talk (ASSET): Leveraging the strengths and resiliencies of sexual minority youth in school-based groups. Journal of LGBT Issues in Counselling, 7(4), 372-386.

Elliot, P., \& Roen, K. (1998). Transgenderism and the question of embodiment: Promising queer politics? GLQ: A Journal of Lesbian and Gay Studies, 4(2), 231-261.

Grace, A. P., \& Wells, K. (2015). Growing into resilience: Sexual and gender minority youth in Canada. Toronto, ON: University of Toronto Press. 
Graybill, E. C., Varjas, K., Meyers, J., Dever, B. V., Greenberg, D., Roach, A. T., \& Morillas, C. (2015). Demographic trends and advocacy experiences of Gay-Straight Alliance advisors. Journal of LGBT Youth, 12(4), 436-461.

Griffin, P., Lee, C., Waugh, J., \& Beyer, C. (2004). Describing roles that Gay-Straight Alliances play in schools: From individual support to social change. Journal of Gay \& Lesbian Issues in Education, 1(3), 7-22. doi:10.1300/J367v01n03_03

Heck, N. C. (2015). The potential to promote resilience: Piloting a minority stress-informed, GSA-based, mental health promotion program for LGBTQ2 youth. Psychology of Sexual Orientation and Gender Diversity, 2(3), 225-231.

Hulko, W., \& Hovanes, J. (2018). Intersectionality in the lives of LGBTQ youth: Identifying as LGBTQ and finding community in small cities and rural towns. Journal of Homosexuality, 65(4), 427-455.

Ioverno, S., Belser, A. B., Baiocco, R., Grossman, A. H., \& Russell, S. T. (2016). The protective role of Gay-Straight Alliances for Lesbian, Gay, Bisexual, and Questioning students: A prospective analysis. Psychology of Sexual Orientation and Gender Diversity, 3(4), 397-406.

Kosciw, J. G., Greytak, E. A., Giga, N. M., Villenas, C., \& Danischewski, D. J. (2016). The 2015 National School Climate Survey: The experiences of lesbian, gay, bisexual, transgender, and queer youth in our nation's schools. New York: GLSEN. Retrieved from https:/www.glsen.org/sites/ default/files/2015\%20National\%20GLSEN\%202015\%20National\%20School\%20Climate\% 20Survey\%20\%28NSCS\%29\%20-\%20Full\%20Report_0.pdf

Kumashiro, K. (2002). Troubling education: Queer activism and anti-oppressive pedagogy. New York, NY: Routledge Falmer.

Lapointe, A. (2017). Teen relationship violence and welling among LGBTQ+ youth. London, ON: Western University. Retrieved from http://www.edu.uwo.ca/csmh/docs/hrpp/knowl edge_summary/teen-relationships-violence-and-wellbeing-among-LGBTQ2-youth.pdf

Lapointe, A., Dunlop, C., \& Crooks, C. (accepted). Feasibility and fit of a mental health promotion program for $L G B T Q+$ youth. Manuscript submitted for publication.

Lee, C. (2002). The impact of belonging to a high school Gay/Straight Alliance. The High School Journal, 85(3), 13-26.

Marx, R. A., \& Kettrey, H. H. (2016). Gay-Straight Alliances are associated with lower levels of school-based victimization of LGBTQ+ Youth: A systematic review and meta-analysis. Journal of Youth and Adolescence, 45(7), 1269-1282.

Mayberry, M., Chenneville, T., \& Currie, S. (2011). Challenging the sounds of silence: A qualitative study of Gay-Straight Alliances and school reform efforts. Education and Urban Society, 45(3), 307-339.

Mayo, C. (2017). Gay-Straight Alliances and associations among youth. New York, NY: Palgrave Macmillan.

Mayo, J. B. (2013). Critical pedagogy enacted in the Gay-Straight Alliance: New possibilities for a third space in teacher development. Educational Researcher, 42(5), 266-275.

Mayo, J. B. (2015). Youth work in Gay-Straight Alliances: Curriculum, pedagogy, and activist development. Child \& Youth Services, 36(1), 79-93.

McCormick, A., Schmidt, K., \& Clifton, E. (2015). Gay-Straight Alliances: Understanding their impact on the academic and social experiences of Lesbian, Gay, Bisexual, Transgender, and Questioning high school students. Children \& Schools, 37(1), 71-77.

McGlashan, H., \& Fitzpatrick, K. (2018). 'I use any pronouns, and I'm questioning everything else': Transgender youth and the issue of gender pronouns. Sex Education: Sexuality, Society and Learning, 18(3). doi:10.1080/14681811.2017.1419949

McGuire, J. K., Dworkin, J., Borden, L. M., Perkins, D., \& Russell, S. T. (2016). Youth motivations for program participation. Journal of Youth Development, 11(3), 7-25. 
Meyer, I. H. (2003). Prejudice, social stress, and mental health in lesbian, gay, and bisexual populations: Conceptual issues and research evidence. Psychological Bulletin, 129(5), 674-697.

Miceli, M. (2005). Standing out, standing together: The social and political impact of gay straight alliances. New York, NY: Taylor and Francis.

Morrison, A. (2012). Examining the usefulness of a gay-straight alliance in an Ontario rural secondary school (Master's thesis). Wilfred Laurier University, Waterloo, Canada.

Patton, M. Q. (2002). Qualitative research \& evaluation methods (3rd ed.). Thousand Oaks, CA: Sage.

Poteat, P. V., \& Scheer, J. R. (2016). GSA advisors' self-efficacy related to LGBT youth of color and transgender youth. Journal of LGBT Youth, 13(4), 311-325.

Poteat, P. V., Scheer, J. R., Marx, R. A., Calzo, J. P., \& Yoshikawa, H. (2015). Gay-Straight Alliances vary in dimensions of youth socializing and advocacy: Factors accounting for individual and setting-level differences. American Journal of Community Psychology, 55(0), 422-432.

Poteat, P. V., Yoshikawa, H., Calzo, J. P., Russell, S. T., \& Horn, S. (2017). Gay-Straight Alliances as settings for youth inclusion and development: Future conceptual and methodological directions for research on these and other student groups in schools. Educational Researcher, 46(9), 508-516.

Poteat, P. V., Calzo, J. P., Yoshikawa, H., Miller, s., Ceccolini, C. J., Rosenbach, S., \& Mauceri, N. (2018). Discussing transgender topics within gay-straight alliances: Factors that could promote more frequent conversations. International Journal of Transgenderism, 1-13. Retrieved from https://www.tandfonline.com/doi/full/10.1080/15532739.2017.1407983

Rood, B. A., Reisner, S. L., Surace, F. I., Puckett Maroney, M. R., \& Pantalone, D. W. (2016). Expecting rejection: Understanding the minority stress experiences of transgender and gender-nonconforming individuals. Transgender Health, 1(1), 151-164.

Sedgwick, E. K. (1990/2008). Epistemology of the closet. Berkley and Los Angeles, CA: University of California Press.

Serano, J. (2007/2016). Whipping girl: A transsexual woman on seism and the scapegoating of femininity (2nd ed.). Berkley, CA: Seal Press.

Sex Ed Plus. (2014). Coming out. Retrieved July 15, 2016 from: http://www.sexedplus.com/com ing-out/

St. John, A., Travers, R., Munro, L., Liboro, R., Schneider, M., \& Greig, C. L. (2014). The success of Gay-Straight Alliances in Waterloo Region, Ontario: A confluence of political and social factors. Journal of LGBT Youth, 11(2), 150-170.

Stryker, S. (2006). (De)Subjugated knowledges: An introduction to transgender studies. In S. Stryker \& S. Whittle (Eds.), The transgender studies reader (pp. 1-17). New York, NY: University Press.

Taylor, C., Peter, T., McMinn, T. L., Elliott, T., Beldom, S., Ferry, A., Gross, Z., Paquin, S., \& Schachter, K. (2011). Every class in every school. The first national climate survey on homophobia, biphobia, and transphobia in Canadian schools. Toronto, ON: EGALE Canada Human Rights Trust. Retrieved from https://egale.ca/wp-content/uploads/2011/05/EgaleFi nalReport-web.pdf

Taylor, C. G., Meyer, E. J., Peter, T., Ristock, J., Short, D., \& Campbell, C. (2016). Gaps between beliefs, perceptions, and practices: The every teacher project on LGBTQ2-inclusive education in Canadian schools. Journal of LGBT Youth, 13(1-2), 112-140.

Toomey, R. B., \& Russell, S. T. (2013). Gay-Straight Alliances, social justice involvement, and school victimization of Lesbian, Gay, Bisexual, and Queer youth: Implications for school well-being and plans to vote. Youth \& Society, 45(4), 500-522. 
Toomey, R. B., Ryan, C., Diaz, R. M., \& Russell, S. T. (2011). High school Gay-Straight Alliances (GSAs) and young adult well-being: An examination of GSA presence, participation, and perceived effectiveness. Applied Developmental Science, 15(4), 175-185.

Toomey, R. B., Ryan, C., Diaz, R. M., \& Russell, S. T. (2017). Coping with sexual orientation-related minority stress. Journal of Homosexuality, 65(4), 1-17. doi:10.1080/00918369.2017.1321888

The Fourth R. (2018). Healthy relationships plus program. Retrieved from http://youthrelation ships.org/hrpp

Valenti, M., \& Campbell, R. (2009). Working with youth on LGBT issues: Why gay-straight alliance advisors become involved. Journal of Community Psychology, 37(2), 228-248.

Walls, E. N., Wisneski, H., \& Kane, S. (2013). School climate, individual support, or both? GayStraight Alliances and the mental health of sexual minority youth. School Social Work Journal, 37(2), 88-111.

\section{Appendix A: Focus group questions}

1. What sessions, topics, or activities did you like the most?

a. Why did you enjoy them?

2. What sessions, topics, or activities did you like the least?

a. Why did you dislike them?

b. How might these sessions, topics, or activities be improved?

3. What was the most important thing that you learned from participating in the HRP for LGBT2Q+ Youth?

4. Has participation in this program positively impacted your relationship with:

a. self (e.g., self-esteem, confidence in abilities, etc.)? Explain.

b. others (e.g., family, friends, peers, teachers, etc.)? Explain.

5. From participating in the program, what did you learn about:

a. Helping yourself?

b. Helping your friends?

c. Was this information useful? Explain.

6. Is there anything else you would like to add or speak about? 